\title{
$A{ }^{140} \mathrm{Nd} /{ }^{140} \mathrm{Pr}$ radionuclide generator based on physico-chemical transitions in ${ }^{140} \mathrm{Pr}$ complexes after electron capture decay of ${ }^{140} \mathrm{Nd}-\mathrm{DOTA}$
}

\author{
By K. P. Zhernosekov ${ }^{1}$, D. V. Filosofov ${ }^{2}$, S. M. Qaim ${ }^{3}$ and F. Rösch ${ }^{1, *}$ \\ ${ }^{1}$ Institut für Kernchemie, Johannes Gutenberg-Universität, 55128 Mainz, Germany \\ 2 Joint Institute of Nuclear Research, Laboratory of Nuclear Problems, 141980 Dubna, Russian Federation \\ ${ }^{3}$ Institut für Nuklearchemie, Forschungszentrum Jülich GmbH, 52425 Jülich, Germany
}

(Received July 1, 2006; accepted in revised form January 2, 2007)

\section{Radionuclide generator / Radiolanthanides / Hot atom chemistry / Radiochemical separation / Positron emission tomography}

\begin{abstract}
Summary. ${ }^{140} \mathrm{Nd}$ was produced by irradiations of $\mathrm{CeO}_{2}$ and $\mathrm{Pr}_{2} \mathrm{O}_{3}$ targets leading to ${ }^{\text {nat }} \mathrm{Ce}\left({ }^{3} \mathrm{He}, x n\right){ }^{140} \mathrm{Nd}$ and ${ }^{141} \operatorname{Pr}(p, 2 n)^{140} \mathrm{Nd}$ nuclear reactions. The practical yield of ${ }^{140} \mathrm{Nd}$ at $\mathrm{EOB}$ in the former reaction over the energy range of $E_{3^{3} \mathrm{He}}=33.5 \rightarrow 0 \mathrm{MeV}$ amounted to $3.5 \mathrm{MBq} / \mu \mathrm{Ah}$ and in the latter reaction over the energy range of $E_{\mathrm{p}}=18.6 \rightarrow 16.2 \mathrm{MeV}$ to $15.5 \mathrm{MBq} / \mu \mathrm{Ah}$. These values correspond to about $41 \%$ and $60 \%$ of the respective theoretical values. Successful separations of the radionuclide were performed by means of cation-exchange chromatography resulting in decontamination factors of $\geq 10^{8}$ and $\geq 7 \times 10^{5}$ for the cerium and praseodymium target materials, respectively. With the no-carrier-added ${ }^{140} \mathrm{Nd}$ obtained, an efficient ${ }^{140} \mathrm{Nd} /{ }^{140} \mathrm{Pr}$ radionuclide generator system was developed and evaluated. The principle of the radiochemical separation is based on physico-chemical transitions (hot-atom effects) of the daughter ${ }^{140} \mathrm{Pr}$ following the electron decay process of ${ }^{140} \mathrm{Nd}$. The parent radionuclide ${ }^{140} \mathrm{Nd}$ (III) is quantitatively adsorbed on a solid phase matrix in the form of ${ }^{140} \mathrm{Nd}$-DOTA-conjugated complexes. The daughter nuclide ${ }^{140} \mathrm{Pr}$ is generated in an ionic species and is easily separated using low volumes of various aqueous eluents. The elution yield is at least $93 \%$, if an optimized eluent, such as DTPA solution is applied. The system remains stable at least over three half-lives of ${ }^{140} \mathrm{Nd}$, with high radiolytic stability and low ${ }^{140} \mathrm{Nd}$ breakthrough. This radionuclide generator system ${ }^{140} \mathrm{Nd}$ $\left(T_{1 / 2}=3.37 \mathrm{~d}\right)$ provides the short-lived positron-emitting radiolanthanide ${ }^{140} \operatorname{Pr}\left(T_{1 / 2}=3.4 \mathrm{~min}\right)$ for molecular imaging using positron emission tomography (PET).
\end{abstract}

\section{Introduction}

A radionuclide generator is a concept based on a nuclear genetic relationship, resulting in a chemical system which permits continuous isolation of a short-lived daughter radionuclide from its long-lived radioactive mother nuclide. Radionuclide generators provide an alternative and often

\footnotetext{
*Author for correspondence (E-mail: frank.roesch@uni-mainz.de).
}

more convenient source of radionuclides compared to direct production routes at rather complex facilities such as accelerators and nuclear reactors.

There are several radiolanthanide generator pairs of interest [1]. Commonly used radionuclide generator systems are based on conventional separation methods (e.g. cationexchange, extraction chromatography, liquid-liquid extraction, etc.), and entail sufficient chemical differences between mother and daughter radionuclides as an essential requirement. If parent/daughter radionuclides are ${ }_{Z} \mathrm{Ln} /{ }_{Z \pm 1} \mathrm{Ln}$ due to the chemical similarity of the two adjacent members of the lanthanide series, however, those radiochemical techniques may not be applicable. Therefore alternative and in principle new radiochemical concepts have to be developed in order to realize the generator systems of radiolanthanides.

${ }^{140} \mathrm{Nd}\left(\mathrm{EC}=100 \%, T_{1 / 2}=3.37 \mathrm{~d}\right)$ produces a shortlived intermediate positron emitter ${ }^{140} \operatorname{Pr}\left(\beta^{+}=49 \%, E_{\max }=\right.$ $2.4 \mathrm{MeV}, T_{1 / 2}=3.4 \mathrm{~min}$ ) which decays to stable ${ }^{140} \mathrm{Ce}$. The pair ${ }^{140} \mathrm{Nd} /{ }^{140} \mathrm{Pr}$ shows potential as a radionuclide generator or as an in vivo generator system for PET $[2,3]$.To develop further the short-lived positron emitter ${ }^{140} \mathrm{Pr}$ for clinical application, a ${ }^{140} \mathrm{Nd} /{ }^{140} \mathrm{Pr}$ radionuclide generator system needs to be designed. For application of the system in the form of an in vivo generator (i.e. direct labelling of biomolecules with the long-lived ${ }^{140} \mathrm{Nd}$ which, after targeting and accumulation at the specific disease sites, generates ${ }^{140} \mathrm{Pr}$ in situ), a consideration of the chemical effects following nuclear transitions is required.

The physico-chemical processes occurring after the primary radioactive decay, such as electron capture (EC) and/or Auger electron emission or X-ray emission, can cause changes in the chemical state of the generated daughter nucleus. In the case of electron capture or internal conversion these "post-effects" are known to provide the possibility of separation of different chemical forms of the parent and daughter radionuclides [4-6]. Attempts to separate neighbouring lanthanides have been reported for several cases as well $[7,8]$. An initial prototype of continuous separation (a radionuclide generator system) of type ${ }_{Z} \mathrm{Ln} /{ }_{\mathrm{Z} \pm 1} \mathrm{Ln}$ was reported for the ${ }^{140} \mathrm{Nd} /{ }^{140} \mathrm{Pr}$ pair [7]. In that work the parent radionuclide ${ }^{140} \mathrm{Nd}$ was adsorbed in the form of a DTPA (diethylene triaminepentaacetic acid) complex 
on an anion-exchanger (Dowex 1, Wofatit SBW). The generated daughter radionuclide ${ }^{140} \mathrm{Pr}$, stabilised in a cationic form, was eluted with $10^{-6} \mathrm{M}$ solution of a carrier (stable lanthanide). This approach provided $30 \pm 15 \%$ yield of the daughter radionuclide. The breakthrough of the parent ${ }^{140} \mathrm{Nd}$ was in the range of $0.2 \%-0.3 \%$.

In the present work we report on a quantitative evaluation of "post-effects" for ${ }^{140} \operatorname{Pr}$ (III) formed following electron capture decay of ${ }^{140} \mathrm{Nd}$-DOTA (DOTA $=1,4,7,10$ tetraazacyclododecane-1,4,7,10-tetraacetic acid). Furthermore an efficient ${ }^{140} \mathrm{Nd} /{ }^{140} \mathrm{Pr}$ radionuclide generator system, based on physico-chemical transitions in this type of complex, is described.

First, the chemical fate of ${ }^{140} \mathrm{Pr}$ is studied by separation of the different chemical forms of the parent and the daughter radionuclides. The daughter ${ }^{140} \mathrm{Pr}$ is released from its chemical micro-environment. DOTA is well known to offer excellent thermodynamic stability and kinetic inertness, particularly for complexes with trivalent metals such as lanthanides [9]. Rapid formation of ${ }^{140} \operatorname{Pr}$-DOTA complex is inhibited by the kinetic inertness of DOTA. The same is true for the radionuclide exchange. Thus, the fraction of "free" ${ }^{140} \mathrm{Pr}$, i.e. non ${ }^{140} \mathrm{Pr}$-DOTA, can be effectively separated from the ${ }^{140} \mathrm{Nd}$-DOTA complex. The other point to realise in the ${ }^{140} \mathrm{Nd} /{ }^{140} \mathrm{Pr}$ radionuclide generator system is (a) to synthesise and (b) to stabilise the parent radionuclide ${ }^{140} \mathrm{Nd}$ in form of a ${ }^{140} \mathrm{Nd}$-DOTA complex on a solid phase. Due to the high thermodynamic stability and kinetic inertness of ${ }^{140} \mathrm{Nd}$ DOTA type complexes (as mentioned above), the release of the long-lived parent radionuclide ${ }^{140} \mathrm{Nd}$ is inhibited at room temperature. ${ }^{140} \mathrm{Nd}$-DOTA or ${ }^{140} \mathrm{Nd}$-DOTA-conjugated compounds are adsorbed on selected resins/cartridges. This immobilises ${ }^{140} \mathrm{Nd}$ and allows an effective continuous separation of ${ }^{140} \mathrm{Pr}$, i.e. representing a ${ }^{140} \mathrm{Nd} /{ }^{140} \mathrm{Pr}$ radionuclide generator system.

\section{Experimental}

\subsection{Reagents and materials}

Only analytical-reagent grade chemicals and Milli-Q water $(18.2 \mathrm{M} \Omega \mathrm{cm})$ were used. Cation-exchange resins BioRad AG 50W-X8, 200-400 mesh and minus 400 mesh, and Aminex A6 were used to prepare chromatography columns. DOTA-DPhe ${ }^{1}-\mathrm{Tyr}^{3}$-octreotide (DOTATOC) was kindly provided by Novartis Pharma AG. For preparation of a ${ }^{140} \mathrm{Nd} /{ }^{140} \mathrm{Pr}$ radionuclide generator, a C-18 cartridge, Phenomenex Strata-X Tube, $30 \mathrm{mg}$, was used.

Complex formation yields were controlled by TLC on aluminium sheets, silica gel 60 , and $0.1 \mathrm{M} \mathrm{Na}_{3}$ Citrate as eluent. Measurement of the radionuclidic composition was done by $\gamma$-ray spectrometry using an HPGe detector.

\subsection{Production of ${ }^{140} \mathrm{Nd}$}

\subsection{1 ${ }^{\text {nat }} \mathrm{Ce}\left({ }^{3} \mathrm{He}, x n\right){ }^{140} \mathrm{Nd}$}

${ }^{140} \mathrm{Nd}$ was produced by irradiation of natural cerium oxide target with ${ }^{3} \mathrm{He}$-particles of $36 \mathrm{MeV}$ primary energy at the CV 28 cyclotron of the Forschungszentrum Jülich as described earlier [2]. The target consisted of $500 \mathrm{mg} \mathrm{CeO}_{2}$ (99.999\%, Sigma Aldrich) and was compressed to a pellet of $13 \mathrm{~mm}$ diameter. The pellet was placed in the groove of a target holder and covered by a $25 \mu \mathrm{m}$ thick $\mathrm{Cu}$ foil. The target holder was cooled by a stream of water flowing at the back. An average beam current of $2.6 \mu \mathrm{A}$ and an irradiation period of 4 hours were applied. A defocussed and wobbled beam was used. The beam current was measured by a charge integrator.

\subsection{2 ${ }^{141} \operatorname{Pr}(p, 2 n)^{140} \mathrm{Nd}$}

In addition, ${ }^{140} \mathrm{Nd}$ was produced by irradiation of praseodymium oxide with protons of $19 \mathrm{MeV}$ primary energy at the CV 28 cyclotron of the Forschungszentrum Jülich. The target consisting of $200 \mathrm{mg} \mathrm{Pr}_{2} \mathrm{O}_{3}$ (99.999\%, Sigma Aldrich) was compressed into a pellet and irradiated in a similar way as in the case of the ${ }^{3} \mathrm{He}$-particle irradiation of $\mathrm{Ce}_{2} \mathrm{O}_{3}$. The beam current used was $3 \mu \mathrm{A}$ and the irradiation time 4 hours.

\subsection{Radiochemical isolation of ${ }^{140} \mathrm{Nd}$ from target materials}

\subsubsection{Chemical separation of n.c.a. ${ }^{140} \mathrm{Nd}(\mathrm{III})$ from macro amounts of $\mathrm{Ce}$ (III)}

The irradiated $\mathrm{Ce}_{2} \mathrm{O}_{3}$ target contained about $35 \mathrm{MBq}$ of ${ }^{140} \mathrm{Nd}$. The activity of the co-produced praseodymium and cerium radionuclides was low, but enough for subsequent $\gamma$-ray spectrometric analysis of the distribution of elements. Radiochemical separation was performed using cationexchange chromatography, according to a $\mathrm{Ce}(\mathrm{III}) / \mathrm{Nd}$ (III) scheme, i.e. not according to the $\mathrm{Ce}(\mathrm{IV}) / \mathrm{Nd}(\mathrm{III})$ separation as used earlier [2]. The irradiated $\mathrm{CeO}_{2}(500 \mathrm{mg}, 2.9 \mathrm{mmol})$ was dissolved in concentrated $\mathrm{HCl}$. The $\mathrm{Ce}(\mathrm{IV})$ was completely reduced to $\mathrm{Ce}(\mathrm{III})$ in the presence of $\mathrm{I}^{-}$ions. The target material was boiled with $\sim 40 \mathrm{ml}$ of concentrated $\mathrm{HCl}$ with addition of $0.5-1 \mathrm{~g}$ KI for $1-1.5 \mathrm{~h}$. After complete dissolution of the target material, the volume was adjusted to $110 \mathrm{ml}$ with $\mathrm{H}_{2} \mathrm{O}$ and filtered on a standard glass filter.

The solution was loaded on a primary chromatography column of $400 \times 20 \mathrm{~mm}$ dimensions, filled with Bio-Rad AG 50W-X8, 200-400 mesh, in hydrogen form. The resin was washed with about $600 \mathrm{ml}$ of $0.5 \mathrm{M} \mathrm{NH}_{4} \mathrm{Cl}$ to convert the cation-exchanger to the $\mathrm{NH}_{4}{ }^{+}$-form. The lanthanides were eluted selectively using $\alpha$-hydroxyisobutyric acid ( $\alpha$-HIBA) solutions of varying concentration at $\mathrm{pH} 4.75$. In order to evaluate the optimum separation condition a gradient elution was applied. Starting with $0.26 \mathrm{M} \alpha$-HIBA, the concentration was increased for each $60 \mathrm{ml}$ eluent (see Fig. 1). The eluate was fractionated in $30 \mathrm{ml}$ portions. Alternatively, the primary chromatography column was loaded with the dissolved target, the resin was washed with $0.5 \mathrm{M} \mathrm{NH}_{4} \mathrm{Cl}$, and $120 \mathrm{ml}$ of $0.20 \mathrm{M} \alpha$-HIBA were applied. The chromatographic separation in this case was performed by isocratic elution (Fig. 2). ${ }^{140} \mathrm{Nd}$ (III) was selectively eluted with $0.30 \mathrm{M} \alpha$-HIBA solution, while Ce(III) was washed out of the resin at a concentration of $0.40 \mathrm{M}$. Next, the ${ }^{140} \mathrm{Nd}$ available was converted to the chloride form. The $\mathrm{pH}$ of the ${ }^{140} \mathrm{Nd}$ (III) solution (150-180 ml, 0.30 M $\alpha$-HIBA) was adjusted to $\sim 1$ by addition of concentrated $\mathrm{HCl}$. The solution was loaded on a cation-exchange chromatography column of $90 \times 8 \mathrm{~mm}$ dimensions, filled with Bio-Rad AG 50W-X8, 


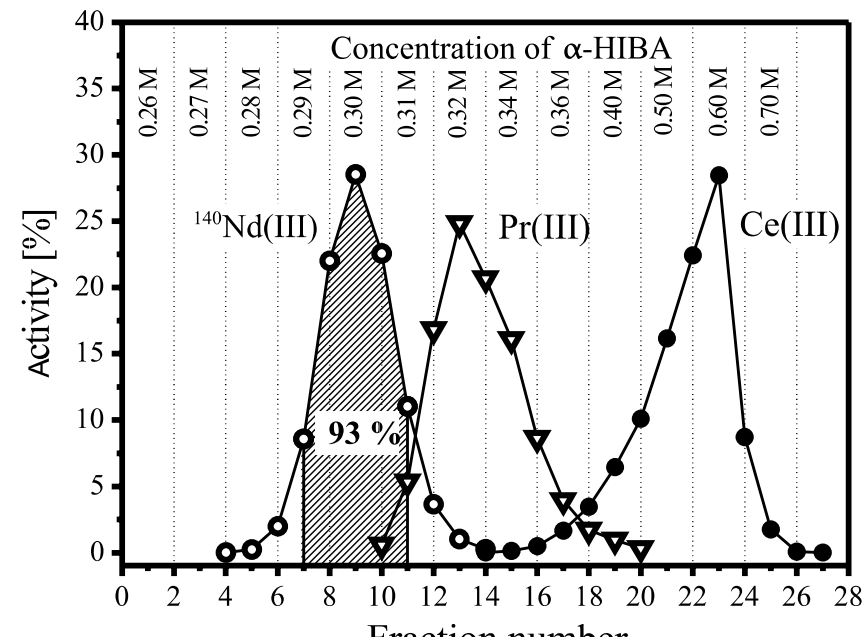

Fraction number

Fig. 1. ${ }^{140} \mathrm{Nd}(\mathrm{III}) / \mathrm{Ce}(\mathrm{III})$ separation. Profiles of a gradient elution on the primary chromatography column $(400 \times 20 \mathrm{~mm}$, AG $50 \mathrm{~W}-\mathrm{X} 8$, 200-400 mesh). Each fraction contained $30 \mathrm{ml}$ of eluted volume.

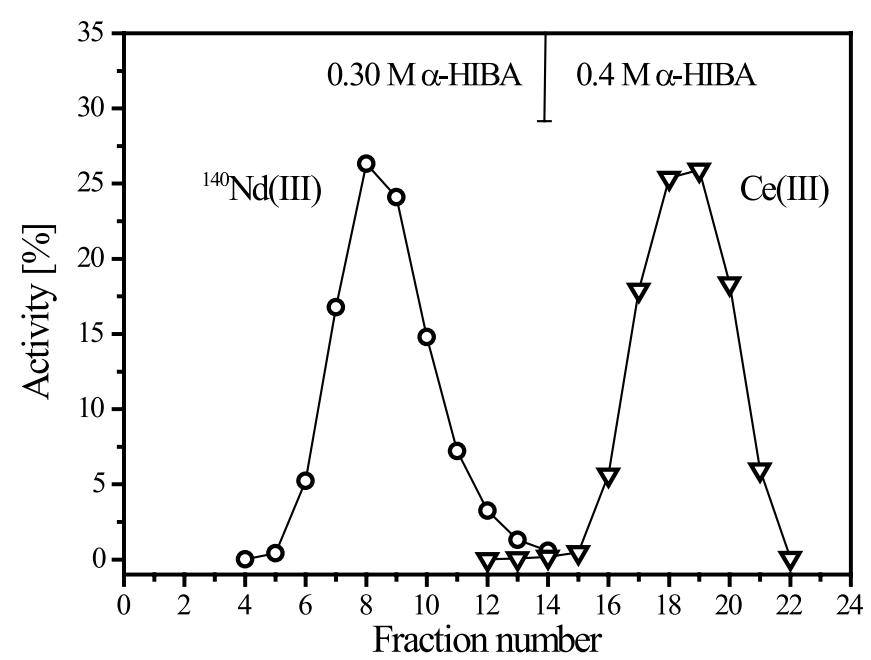

Fig. 2. ${ }^{140} \mathrm{Nd}(\mathrm{III}) / \mathrm{Ce}$ (III) separation. Profiles of an isocratic elution on the primary chromatography column $(400 \times 20 \mathrm{~mm}$, AG $50 \mathrm{~W}-\mathrm{X} 8$, $200-400 \mathrm{mesh}$ ). Each fraction contained $30 \mathrm{ml}$ of eluted volume.

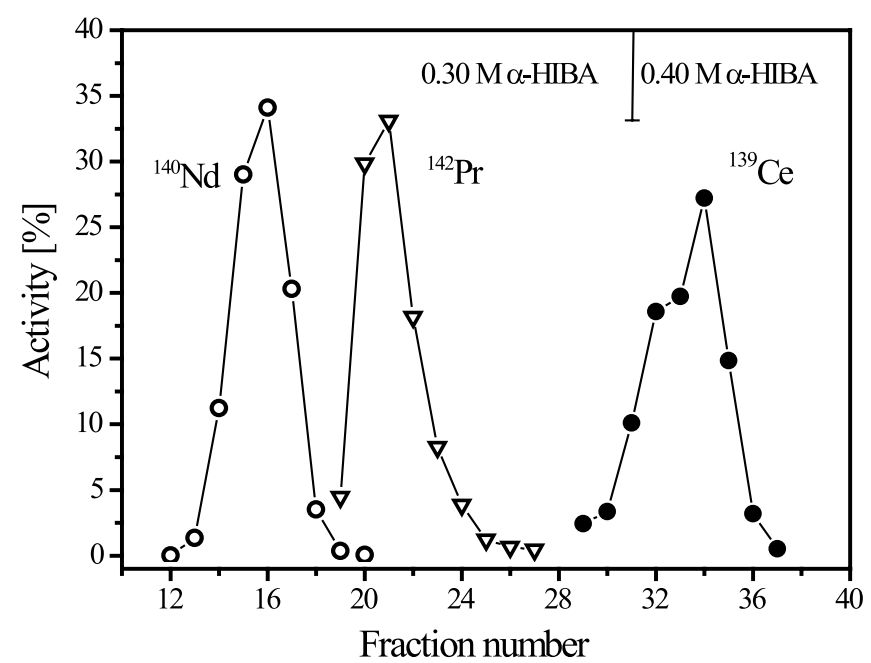

Fig. 3. ${ }^{140} \mathrm{Nd}(\mathrm{III}) / \mathrm{Ce}$ (III) separation. Profiles of isocratic elution on the small chromatography column $(100 \times 2 \mathrm{~mm}$, Aminex A6). Each fraction contained 2 drops $(\sim 60 \mu \mathrm{l})$ of eluted volume. The fractions 13 to 18 were collected to obtain pure ${ }^{140} \mathrm{Nd}$.
200-400 mesh, hydrogen form. The resin was washed with $1 \mathrm{M} \mathrm{HCl} .{ }^{140} \mathrm{Nd}(\mathrm{III})$ was eluted with about $20 \mathrm{ml}$ of $4 \mathrm{M}$ $\mathrm{HCl}$. After evaporation the activity was collected in $\sim 1 \mathrm{ml}$ of $0.1 \mathrm{M} \mathrm{HCl}$.

The final purification of ${ }^{140} \mathrm{Nd}(\mathrm{III})$ was performed on a small Aminex A6 column $(100 \times 2 \mathrm{~mm})$. The activity was loaded on the resin in hydrogen form from the $0.1 \mathrm{M} \mathrm{HCl}$ solution. The resin was washed with $0.5 \mathrm{M} \mathrm{NH}_{4} \mathrm{Cl}$ and $0.20 \mathrm{M}$ $\alpha$-HIBA. ${ }^{140} \mathrm{Nd}$ (III) was selectively eluted with $0.30 \mathrm{M}$ $\alpha$-HIBA in a $60 \mu \mathrm{l}$ fraction. The co-produced praseodymium radioisotopes are separated as well. The remaining $\mathrm{Ce}(\mathrm{III})$ was washed out again with $0.40 \mathrm{M} \alpha$-HIBA. An example of the elution profile is shown in Fig. 3.

\subsubsection{Chemical separation of n.c.a. ${ }^{140} \mathrm{Nd}$ (III) from macro amounts of $\operatorname{Pr}($ III)}

Following ${ }^{141} \operatorname{Pr}(p, 2 n)$ production, about $200 \mathrm{MBq}$ of ${ }^{140} \mathrm{Nd}$ were available. As no Pr radioisotope was co-produced in adequate amount, ${ }^{142} \operatorname{Pr}\left(T_{1 / 2}=19.13 \mathrm{~h}\right)$ was separately produced for $\gamma$-ray spectrometric analysis of the distribution of elements. Praseodymium chloride $(5 \mathrm{mg})$ was irradiated at the TRIGA II reactor in Mainz at a neutron flux of $4 \times 10^{12} \mathrm{~cm}^{-2} \mathrm{~s}^{-1}$ for $3 \mathrm{~h}$, resulting in $93 \mathrm{MBq}$ of ${ }^{142} \mathrm{Pr}$. Radiochemical separation was performed using cationexchange chromatography.

The cyclotron irradiated target material $\left(200 \mathrm{mg} \operatorname{Pr}_{2} \mathrm{O}_{3}\right.$, $0.6 \mathrm{mmol}$ ) was dissolved in $5 \mathrm{ml}$ of concentrated $\mathrm{HCl}$ by heating $\left(50-60^{\circ} \mathrm{C}\right)$ for $20-30 \mathrm{~min}$. After addition of ${ }^{142 / 141} \mathrm{PrCl}_{3}$ and $5 \mathrm{mmol}$ of $\mathrm{NH}_{4} \mathrm{Cl}$, the mixture was evaporated under argon atmosphere. The dried residue was dissolved in $20 \mathrm{ml}$ of $\mathrm{H}_{2} \mathrm{O}$. Due to the remaining $\mathrm{HCl}$, the $\mathrm{pH}$ of the solution was 1-2. The mixture was passed through a standard glass filter.

The primary chromatography column was of $390 \times$ $16 \mathrm{~mm}\left(V_{\mathrm{fr}} \sim 80 \mathrm{ml}\right)$ dimensions, filled with Bio-Rad AG 50W-X8, 200-400 mesh. In contrast to the protocol used for separating ${ }^{140} \mathrm{Nd}$ from $\mathrm{Ce}(\mathrm{III})$, the resin was prepared in the $\mathrm{NH}_{4}{ }^{+}$-form. After loading the column with the dissolved target solution, it was washed with $120 \mathrm{ml}$ of $0.20 \mathrm{M}$

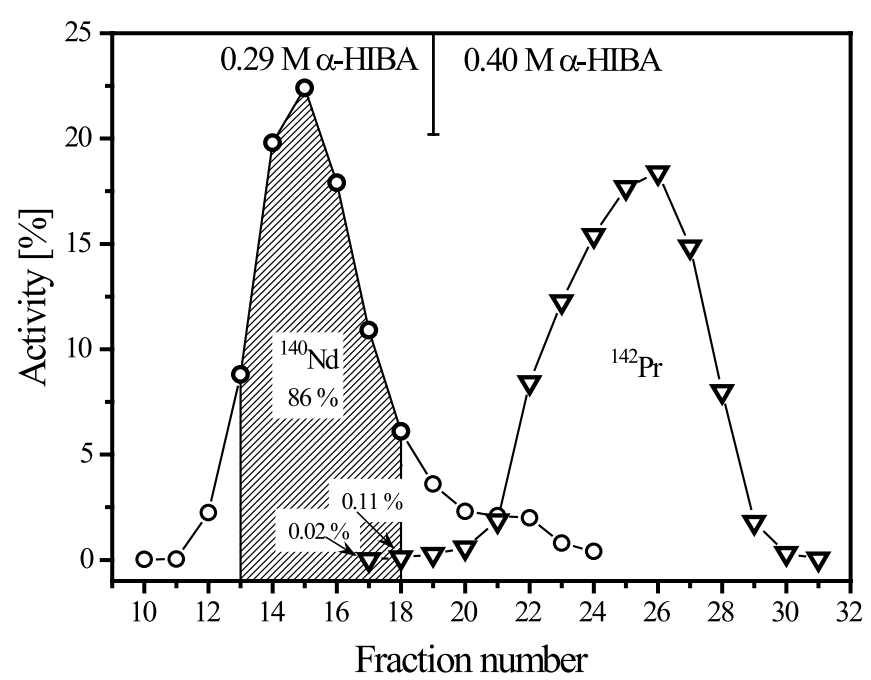

Fig. 4. ${ }^{140} \mathrm{Nd}(\mathrm{III}) / \operatorname{Pr}(\mathrm{III})$ separation. Profiles of an isocratic elution on the primary chromatography column $(390 \times 16.1 \mathrm{~mm}$, AG $50 \mathrm{~W}-\mathrm{X} 8$, $200-400$ mesh). Each fraction contained $12 \mathrm{ml}$ of eluted volume. 


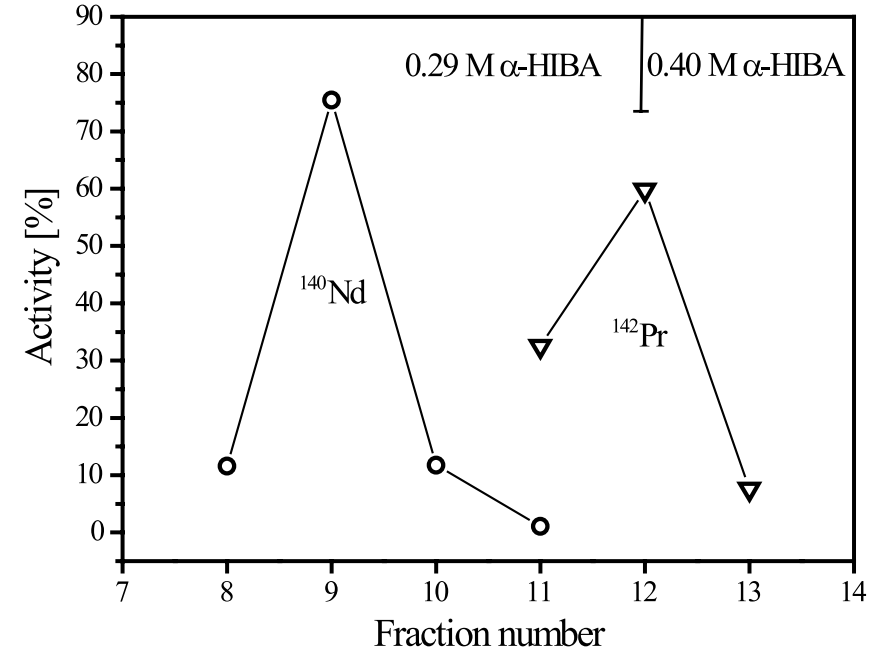

Fig. 5. ${ }^{140} \mathrm{Nd}(\mathrm{III}) / \operatorname{Pr}(\mathrm{III})$ separation. Profiles of isocratic elution on the small chromatography column $(100 \times 2 \mathrm{~mm}$, Aminex A6). Each fraction contained 3 drops $(\sim 90 \mu \mathrm{l})$ of eluted volume. The fractions 8 to 10 were collected to obtain pure ${ }^{140} \mathrm{Nd}$.

$\alpha$-HIBA solution. The chromatographic separation was performed by isocratic elution (Fig. 4). Each fraction contained $12 \mathrm{ml}$ of the eluate. ${ }^{140} \mathrm{Nd}$ (III) was selectively eluted with $0.29 \mathrm{M} \alpha$-HIBA solution whereas $\operatorname{Pr}(\mathrm{III})$ was washed out at an $\alpha$-HIBA concentration of $0.40 \mathrm{M}$. The ${ }^{140} \mathrm{Nd}$ (III) available was converted to its chloride form using a medium chromatography column $90 \times 5 \mathrm{~mm}$, filled with Bio-Rad AG 50W-X8, 200-400 mesh, hydrogen form, as described above (see Sect. 2.3.1). The ${ }^{140} \mathrm{Nd}$ activity was obtained in $1 \mathrm{ml}$ of a $0.25 \mathrm{M} \mathrm{HCl}$ solution.

Final purification of ${ }^{140} \mathrm{Nd}$ (III) was performed on a small Aminex A6 column $(100 \times 2 \mathrm{~mm})$. The activity was loaded on the resin in hydrogen form from the $0.25 \mathrm{M} \mathrm{HCl}$ solution. Thereafter the resin was washed with $0.5 \mathrm{M} \mathrm{NH}_{4} \mathrm{Cl}$ and $0.20 \mathrm{M} \alpha$-HIBA. The ${ }^{140} \mathrm{Nd}$ (III) was selectively eluted with $0.29 \mathrm{M} \alpha$-HIBA whereas $\operatorname{Pr}(\mathrm{III})$ was washed out at the concentration 0.40 M $\alpha$-HIBA (Fig. 5).

\subsection{Investigation of the chemical fate of ${ }^{140} \mathrm{Pr}$ in aqueous solutions}

After the final purification on the small cation-exchange chromatography column (Figs. 3, 5), the ${ }^{140} \mathrm{Nd}$ activity was obtained in a small volume of the $0.29-0.30 \mathrm{M} \alpha$ HIBA eluate. It was diluted with $300 \mu \mathrm{l}$ of $\mathrm{H}_{2} \mathrm{O}$ and taken directly for preparation of the ${ }^{140} \mathrm{Nd}$-DOTA complex. About 1-3 nmol of DOTA was added to the ${ }^{140} \mathrm{Nd}$ solution and the mixture was heated at $\sim 100{ }^{\circ} \mathrm{C}$ for about $30 \mathrm{~min}$. The complex formation yield was controlled by TLC (aluminium sheets silica gel 60; $0.1 \mathrm{M} \mathrm{Na}_{3}$ Citrate eluent). The procedure was repeated (if needed) until the labelling yield was $\simeq 90 \%$. This procedure allowed preparation of the ${ }^{140} \mathrm{Nd}$-DOTA complex without excess of the free ligand DOTA. The separation of ${ }^{140} \mathrm{Nd}$-DOTA from $\simeq 10 \%$ of uncomplexed ${ }^{140} \mathrm{Nd}$ (III) was performed on a micro-chromatography column, prepared using $50 \mathrm{mg}$ of Bio-Rad AG 50W-X8 cation exchanger, minus 400 mesh. Reaction mixtures were passed through the column in $\mathrm{NH}_{4}{ }^{+}$-form. Free ${ }^{140} \mathrm{Nd}$ (III) was quantitatively adsorbed on the resin while the ${ }^{140} \mathrm{Nd}$-DOTA complex (1:1 stoichiometry without excess of the ligand) was obtained in the eluate. The $\alpha$-HIBA content in the mixture was negligible.

In order to determine the release of ${ }^{140} \operatorname{Pr}(\mathrm{III})$ from the DOTA complex, ${ }^{140} \mathrm{Nd} /{ }^{140} \mathrm{Pr}$-DOTA (1: 1 stoichiometry) aqueous solutions with activities of $1-2 \mathrm{MBq}{ }^{140} \mathrm{Nd}$ were passed through the micro-chromatography column at room temperature. The column was additionally washed with $300 \mu \mathrm{l}$ of water. The procedure could be performed within $10-15$ s only. Free stabilized ${ }^{140} \operatorname{Pr}$ (III) was quantitatively adsorbed on the resin, while ${ }^{140} \mathrm{Nd}$-DOTA passed through the column with the eluate. The accumulation of ${ }^{140} \mathrm{Pr}$ in the eluted ${ }^{140} \mathrm{Nd}$ fraction was studied by HPGe detector $\gamma$-ray spectrometry, using the intense $511 \mathrm{keV}$ annihilation peak associated with the positron decay of ${ }^{140} \mathrm{Pr}$. A series of $25 \mathrm{~s}$ measurements were performed until an equilibrium in the ${ }^{140} \mathrm{Nd} /{ }^{140} \mathrm{Pr}$ generator system was achieved.

\section{$2.5{ }^{140} \mathrm{Nd} /{ }^{140} \mathrm{Pr}$ radionuclide generator}

The ${ }^{140} \mathrm{Nd}$-DOTATOC complex was prepared in aqueous solution containing 1 to $100 \mu \mathrm{g}$ of DOTATOC (mainly depending on the specific activity of ${ }^{140} \mathrm{Nd}$ ) as described above. With $\sim 95 \%$ reaction yield the mixture represented $95 \%$ of the ${ }^{140} \mathrm{Nd}$-DOTATOC complex at $1: 1$ stoichiometry and $5 \%$ of free ${ }^{140} \mathrm{Nd}$ (III) without excess of the ligand DOTATOC. For preparation of a ${ }^{140} \mathrm{Nd} /{ }^{140} \mathrm{Pr}$ radionuclide generator system, about $2.15 \mathrm{MBq}$ of the ${ }^{140} \mathrm{Nd}$-DOTATOC was loaded on a C-18 cartridge, Phenomenex Strata-X tubes, $30 \mathrm{mg} .{ }^{140} \mathrm{Nd}$-DOTATOC was adsorbed quantitatively on the solid phase. The cartridge was washed with $5 \mathrm{ml}$ of $10^{-3} \mathrm{M}$ DTPA, pH 6.2, in order to remove the $5 \%$ free ${ }^{140} \mathrm{Nd}(\mathrm{III})$. The cartridge itself became the column of the radionuclide generator system. It could be operated with standard single-use syringes. As eluent system, aqueous solutions of $10^{-7}-10^{-3} \mathrm{M}$ DTPA, $10^{-3}-10^{-1} \mathrm{M}$ citrate and $10^{-3} \mathrm{M}$ NTA $(\mathrm{pH} \sim 6.0)$ were examined. The cartridge was eluted with $1 \mathrm{ml}$ each of these mixtures. The procedure could be performed within about $10 \mathrm{~s}$ only. Between successive elutions, the generator was washed with water and kept in pure water.

\section{Results and discussion}

\section{1 ${ }^{140} \mathrm{Nd}$ production}

${ }^{140} \mathrm{Nd}\left(T_{1 / 2}=3.37 \mathrm{~d}\right)$ can be produced by (i) irradiation of ${ }^{141} \mathrm{Pr}$ with protons $\left({ }^{141} \operatorname{Pr}(p, 2 n)^{140} \mathrm{Nd}\right)$ or deuterons $\left({ }^{141} \operatorname{Pr}(d, 3 n){ }^{140} \mathrm{Nd}\right)$ and (ii) ${ }^{3} \mathrm{He}-$ or ${ }^{4} \mathrm{He}$-induced nuclear reactions on ${ }^{140} \mathrm{Ce}$ such as ${ }^{140} \mathrm{Ce}\left({ }^{3} \mathrm{He}, 3 n\right){ }^{140} \mathrm{Nd}$ or ${ }^{140} \mathrm{Ce}$ $\left({ }^{4} \mathrm{He}, 4 n\right){ }^{140} \mathrm{Nd}$. In both cases elements of natural isotopic composition, viz. ${ }^{\text {nat }} \mathrm{Ce}\left(0.19 \%{ }^{136} \mathrm{Ce} ; 0.25 \%{ }^{138} \mathrm{Ce} ; 88.5 \%\right.$ $\left.{ }^{140} \mathrm{Ce} ; 11.08 \%{ }^{142} \mathrm{Ce}\right)$ and ${ }^{\text {nat }} \operatorname{Pr}\left(100 \%{ }^{141} \mathrm{Pr}\right)$ can be used as target material.

A detailed study of the nuclear reactions ${ }^{\text {nat }} \mathrm{Ce}\left({ }^{3} \mathrm{He}, x n\right)$ ${ }^{140} \mathrm{Nd}$ and ${ }^{141} \operatorname{Pr}(p, 2 n){ }^{140} \mathrm{Nd}$ was published recently [10]. The yields of ${ }^{140} \mathrm{Nd}$ calculated from the excitation functions were found to be $12 \mathrm{MBq} / \mu \mathrm{Ah}$ if cerium is irradiated with ${ }^{3} \mathrm{He}$ particles $(E=35 \rightarrow 20 \mathrm{MeV})$ and $210 \mathrm{MBq} / \mu \mathrm{A}$ h when $\mathrm{Pr}$ is irradiated with protons $(E=30 \rightarrow 15 \mathrm{MeV})$. 
Table 1. Possible nuclear processes and their products (with $T_{1 / 2}>1 \mathrm{~h}$ ) in the interactions of $36 \mathrm{MeV}{ }^{3} \mathrm{He}$-particles with ${ }^{\text {nat }} \mathrm{Ce}$ and of $19 \mathrm{MeV}$ protons with ${ }^{141} \mathrm{Pr}$.

\begin{tabular}{|c|c|c|c|}
\hline \multirow[t]{2}{*}{ Radionuclide $^{a}$} & \multirow[t]{2}{*}{$T_{1 / 2}$} & \multicolumn{2}{|c|}{ Nuclear processes on targets } \\
\hline & & ${ }^{\text {nat }} \mathrm{Ce}$ & ${ }^{141} \mathrm{Pr}$ \\
\hline${ }^{141} \mathrm{Nd}$ & $2.5 \mathrm{~h}$ & $\begin{array}{l}{ }^{140} \mathrm{Ce}\left({ }^{3} \mathrm{He}, 2 n\right) \\
{ }^{142} \mathrm{Ce}\left({ }^{3} \mathrm{He}, 4 n\right)\end{array}$ & ${ }^{141} \operatorname{Pr}(p, n)$ \\
\hline${ }^{140} \mathrm{Nd}$ & $3.37 \mathrm{~d}$ & $\begin{array}{l}{ }^{140} \mathrm{Ce}\left({ }^{3} \mathrm{He}, 3 n\right) \\
{ }^{138} \mathrm{Ce}\left({ }^{3} \mathrm{He}, n\right)\end{array}$ & ${ }^{141} \operatorname{Pr}(p, 2 n)$ \\
\hline${ }^{139 \mathrm{~m}} \mathrm{Nd}$ & $5.5 \mathrm{~h}$ & $\begin{array}{l}{ }^{140} \mathrm{Ce}\left({ }^{3} \mathrm{He}, 4 n\right) \\
{ }^{138} \mathrm{Ce}\left({ }^{3} \mathrm{He}, 2 n\right)\end{array}$ & \\
\hline${ }^{139} \mathrm{Pr}$ & $4.5 \mathrm{~h}$ & $\begin{array}{l}{ }^{140} \mathrm{Ce}\left({ }^{3} \mathrm{He}, p 3 n\right) \\
{ }^{138} \mathrm{Ce}\left({ }^{3} \mathrm{He}, p n\right)\end{array}$ & ${ }^{141} \operatorname{Pr}(p, t)$ \\
\hline${ }^{142} \mathrm{Pr}$ & $19.1 \mathrm{~h}$ & $\begin{array}{l}{ }^{140} \mathrm{Ce}\left({ }^{3} \mathrm{He}, p\right) \\
{ }^{142} \mathrm{Ce}\left({ }^{3} \mathrm{He}, p 2 n\right)\end{array}$ & \\
\hline${ }^{143} \mathrm{Pr}$ & $13.6 \mathrm{~d}$ & ${ }^{142} \mathrm{Ce}\left({ }^{3} \mathrm{He}, p n\right)$ & \\
\hline${ }^{139} \mathrm{Ce}$ & $137.6 \mathrm{~d}$ & $\begin{array}{l}{ }^{138} \mathrm{Ce}\left({ }^{3} \mathrm{He}, 2 p\right) \\
{ }^{140} \mathrm{Ce}\left({ }^{3} \mathrm{He}, \alpha\right)\end{array}$ & ${ }^{139} \operatorname{Pr}\left(\mathrm{EC}, \beta^{+}\right)$ \\
\hline${ }^{141} \mathrm{Ce}$ & $32.5 \mathrm{~d}$ & $\begin{array}{l}{ }^{140} \mathrm{Ce}\left({ }^{3} \mathrm{He}, 2 p\right) \\
{ }^{142} \mathrm{Ce}\left({ }^{3} \mathrm{He}, \alpha\right)\end{array}$ & \\
\hline${ }^{143} \mathrm{Ce}$ & $33.0 \mathrm{~h}$ & ${ }^{142} \mathrm{Ce}\left({ }^{3} \mathrm{He}, 2 p\right)$ & \\
\hline
\end{tabular}

a: Decay data takes from the Table of Radioactive Isotopes (E. Browne and R. B. Firestone), Wiley, 1986 [11].

The radionuclides, co-produced with ${ }^{140} \mathrm{Nd}$ in the interactions of ${ }^{3} \mathrm{He}$-particles with ${ }^{\text {nat }} \mathrm{Ce}$ and of protons with ${ }^{141} \mathrm{Pr}$, are listed in Table 1 . The corresponding nuclear reactions are also given. Due to the higher energy of the ${ }^{3} \mathrm{He}$-particles used $(36 \mathrm{MeV})$ and the four stable isotopes in ${ }^{\text {nat }} \mathrm{Ce}$, the number of possible reaction channels is high. In the case of nat $\mathrm{Pr}$ the energy of protons used was only $19 \mathrm{MeV}$ and the target is monoisotopic; the number of possible reactions was therefore low. The radionuclides detected in the cerium target about 40 hours after the end of irradiation are listed in Table 2. Their estimated activities are also given.

The radionuclide ${ }^{140} \mathrm{Nd}$ can be achieved in high radionuclidic purity via both routes due to the absence of any long-lived co-produced Nd-isotope. The longest-lived ${ }^{139 \mathrm{~m}} \mathrm{Nd}$ (EC, $T_{1 / 2}=5.5 \mathrm{~h}$ ) will be present only in negligible amounts at the end of the target processing (1-2 days after EOB). However, for in vivo application of ${ }^{140} \mathrm{Nd}$, the relatively long-lived ${ }^{143} \operatorname{Pr}\left(\beta^{-}, E_{\max }=0.9 \mathrm{MeV}, T_{1 / 2}=\right.$ $13.57 \mathrm{~d}$ ) might be a critical contaminant associated with the ${ }^{n a t} \mathrm{Ce}\left({ }^{3} \mathrm{He}, x n\right)$ route. Thus, a special purification of ${ }^{140} \mathrm{Nd}$ from praseodymium should be taken into consideration, although the basic radiochemical separation strategy aims at the isolation of ${ }^{140} \mathrm{Nd}$ from macro-amounts of cerium.

\subsubsection{Chemical separation of n.c.a. ${ }^{140} \mathrm{Nd}$ (III) from macro amounts of $\mathrm{Ce}(\mathrm{III})$}

As mentioned in Sect. 2.3.1, ${ }^{140} \mathrm{Nd}$ (III) was effectively eluted from the cation-exchanger in $0.29-0.30 \mathrm{M} \alpha$-HIBA solution, whereas $\mathrm{Ce}$ (III) was obtained in $\alpha$-HIBA solutions with concentrations above $0.40 \mathrm{M}$. After these steps about $90 \%$ of ${ }^{140} \mathrm{Nd}$ (III) could be obtained with an estimated amount of $\mathrm{Ce}(\mathrm{III})$ of $\sim 41 \mu \mathrm{g}$, thus leading to a reduction by a factor of $\sim 10^{4}$ (i.e. $406 \mathrm{mg} \rightarrow \sim 41 \mu \mathrm{g}$ ). The separation efficacy of the $\mathrm{Nd}(\mathrm{III}) / \mathrm{Pr}(\mathrm{III})$ pair, on the other hand, was poorer (Fig. 1). Praseodymium was washed out already in the range of the concentration 0.31-0.32 M $\alpha$-HIBA. Nevertheless, the content of $\operatorname{Pr}(\mathrm{III})$ was reduced by a factor of around 20 . The second purification step via the small chromatographic column yielded additional decontamination factors $>10^{4}$ and $\sim 10^{2}$ for $\mathrm{Ce}(\mathrm{III})$ and $\operatorname{Pr}(\mathrm{III})$, respectively. An example of the elution profile is shown in Fig. 3.

The present two-step route of purification of ${ }^{140} \mathrm{Nd}(\mathrm{III})$ from macro amounts of $\mathrm{Ce}$ (III) provided an overall decontamination factor $>10^{8}$, i.e. resulting in $\leq 4 \mathrm{ng}$ of cerium remaining. The praseodymium amount was reduced down to $0.05 \%$. The complete radiochemical procedure lasted $1-2$ days with an overall yield of ${ }^{140} \mathrm{Nd}$ of about $90 \%$.
Table 2. Radionuclides detected in the ${ }^{\text {nat }} \mathrm{Ce}$ target irradiated with $36 \mathrm{MeV}{ }^{3} \mathrm{He}-$ particles.

\begin{tabular}{lcccc}
\hline Radionuclide & $T_{1 / 2}$ & $\begin{array}{c}\text { Activity } \\
{[\mathrm{kBq}]}\end{array}$ & $\begin{array}{c}E_{\gamma} \text { used for } \\
\text { quantification }[\mathrm{keV}]\end{array}$ & $\begin{array}{c}I_{\gamma} \\
(\%)\end{array}$ \\
\hline${ }^{140} \mathrm{Nd}$ & $3.37 \mathrm{~d}$ & $12500-15600^{b}$ & 1596.5 & 0.5 \\
\hline${ }^{139 \mathrm{~m}} \mathrm{Nd}$ & $5.5 \mathrm{~h}$ & $400-2100$ & 113.9 & 34.0 \\
& & & 938.2 & 30.0 \\
& $19.1 \mathrm{~h}$ & $2100-2300$ & 1575.7 & 3.7 \\
\hline${ }^{142} \mathrm{Pr}$ & $137.6 \mathrm{~d}$ & $33-95$ & 165.8 & 79.9 \\
\hline${ }^{139} \mathrm{Ce}$ & $32.5 \mathrm{~d}$ & $99-113$ & 145.4 & 48.4 \\
\hline${ }^{141} \mathrm{Ce}$ & $33.0 \mathrm{~h}$ & $170-180$ & 293.3 & 42.0 \\
\hline${ }^{143} \mathrm{Ce}$ & & & 722.0 & 5.1 \\
\hline
\end{tabular}

a: Measured about 40 hours after the end of irradiation;

b: The uncertainly in the estimated radioactivity is rather high since the intensity of the $1596.5 \mathrm{keV}$ $\gamma$-ray used is very low. This $\gamma$-ray is emitted by the daughter ${ }^{140} \operatorname{Pr}\left(T_{1 / 2}=3.4 \mathrm{~min}\right)$ which is in transient equilibrium with the parent ${ }^{140} \mathrm{Nd}$. 


\subsubsection{Chemical separation of n.c.a. ${ }^{140} \mathrm{Nd}$ (III) from macro amounts of $\operatorname{Pr}($ III)}

After processing the ${ }^{140} \mathrm{Nd}(\mathrm{III}) / \operatorname{Pr}(\mathrm{III})$ lanthanide pair on the primary chromatography column (Fig. 4) about 85\% of ${ }^{140} \mathrm{Nd}$ (III) could be obtained with an estimated amount of $121 \mu \mathrm{g}$ of $\operatorname{Pr}(\mathrm{III})$, i.e. reduced by a factor of $\sim 7 \times 10^{2}$ $(85 \mathrm{mg} \rightarrow 121 \mu \mathrm{g})$. The estimated decontamination factor of ${ }^{140} \mathrm{Nd}(\mathrm{IIII})$ from $\operatorname{Pr}(\mathrm{III})$ after the final purification step (Fig. 5) was $>10^{3}$. The activity of ${ }^{142} \mathrm{Pr}$ detected in the eluate after processing on the small column corresponded only to about $8 \mu \mathrm{g}$ of the metal. Therefore, the separation n.c.a. ${ }^{140} \mathrm{Nd}$ (III) /macroscopic $\operatorname{Pr}$ (III) lanthanide pair is performed by a two-step route. An overall decontamination factor of $>7 \times 10^{5}$ could be achieved, i.e. $\leq 0.1 \mu \mathrm{g}$ of praseodymium remained in ${ }^{140} \mathrm{Nd}$. The complete radiochemical procedure lasted 1-2 days and the overall yield of ${ }^{140} \mathrm{Nd}$ was about $90 \%$.

\subsubsection{Comparison of production routes}

\section{Radiochemistry}

The isolation of ${ }^{140} \mathrm{Nd}$ (III) by means of cation-exchange chromatography from the target lanthanide material is evidently more efficient if $\mathrm{CeO}_{2}$ is irradiated (decontamination factor $\left.\geq 10^{8}\right)$. An efficient purification of ${ }^{140} \mathrm{Nd}$ could also be performed from macro amounts of $\operatorname{Pr}(\mathrm{III})$, but the decontamination factor of $\geq 7 \times 10^{5}$ is evidently lower due to the direct neighbouring existence of n.c.a. ${ }^{140} \mathrm{Nd}$ and macroscopic $\operatorname{Pr}(\Delta Z=1)$ in the Periodic Table of Elements. For the system n.c.a. ${ }^{140} \mathrm{Nd} /$ macroscopic Ce, the $\Delta Z$ value is 2 . In both cases the amount of the target material remaining in the separated product was below $1 \mathrm{nmol}$. The time needed for the two procedures was the same.

Processing of the praseodymium target was performed under optimized conditions. The dissolved target was loaded on to the cation-exchanger directly in $\mathrm{NH}_{4}{ }^{+}$-form. This approach avoids erosion of the loading zone and reduces time of processing and volume of radioactive liquid waste.

\section{Radionuclide production yield}

As mentioned above, the theoretical yield of ${ }^{140} \mathrm{Nd}$ via the ${ }^{141} \operatorname{Pr}(p, 2 n)$ reaction at $30 \mathrm{MeV}$ is by a factor of about 18 higher than that via the ${ }^{\text {nat }} \mathrm{Ce}\left({ }^{3} \mathrm{He}, x n\right)$ reaction at $33.5 \mathrm{MeV}$. However, since the proton energy available at the CV 28 was only $19 \mathrm{MeV}$, the expected yield of ${ }^{140} \mathrm{Nd}$ via the $(p, 2 n)$ reaction over the energy range $(E=18.6 \rightarrow 16.2 \mathrm{MeV})$ was about $30 \mathrm{MBq} / \mu \mathrm{Ah}[10]$, i.e. by a factor of about 3 higher than via the $\left({ }^{3} \mathrm{He}, x n\right)$ reaction. The practically achieved ${ }^{140} \mathrm{Nd}$ yields at EOB were about $3.5 \mathrm{MBq} / \mu \mathrm{Ah}$ and $15.5 \mathrm{MBq} / \mu \mathrm{Ah}$ in the ${ }^{\text {nat }} \mathrm{Ce}\left({ }^{3} \mathrm{He}, x n\right)$ and ${ }^{141} \operatorname{Pr}(p, 2 n)$ processes, respectively. Considering the chemical compositions of the target materials and the projectile energies effective in those targets, the practical yield values correspond to about $41 \%$ and $60 \%$ of the respective theoretical values [10]. The relatively low experimental values are possibly due to the use of wobbled and defocussed beam as well as due to radiation damage. These factors appear to be more pronounced in the case of ${ }^{3} \mathrm{He}$-particle. In view of the much higher ${ }^{140} \mathrm{Nd}$ overall yield and an efficient isolation possibility, the ${ }^{141} \operatorname{Pr}(p, 2 n)^{140} \mathrm{Nd}$ production route seems to be su- perior even at $19 \mathrm{MeV}$ compared to the ${ }^{\text {nat }} \mathrm{Ce}\left({ }^{3} \mathrm{He}, x n\right){ }^{140} \mathrm{Nd}$ route. ${ }^{140} \mathrm{Nd}$ can be produced with high specific activity and chemical/radiochemical purity for preparation of metalloradiopharmaceuticals.

\subsection{Chemical fate of ${ }^{140} \mathrm{Pr}$ in aqueous solutions}

The chemical fate of ${ }^{140} \mathrm{Pr}$ in aqueous solutions was studied by separation of the different chemical forms of the parent and the daughter radionuclides. The principle of the ${ }^{140} \mathrm{Pr}$ release is illustrated in Fig. 6. Due to post-effects following the electron capture decay of the parent ${ }^{140} \mathrm{Nd},{ }^{140} \mathrm{Pr}$ is formed in a different chemical form (i.e. not as ${ }^{140} \mathrm{Pr}$-DOTA species). It is therefore chemically separable from its parent radionuclide.

After absorption of ${ }^{140} \mathrm{Nd}$-DOTA on the micro-chromatography column, ${ }^{140} \mathrm{Pr}$ is generated from ${ }^{140} \mathrm{Nd}$. The accumulation of this ${ }^{140} \mathrm{Pr}$ generated in the eluted ${ }^{140} \mathrm{Nd}$-DOTA fractions was studied.

The occurrence of ${ }^{140} \mathrm{Pr}$ activity $A_{140 \mathrm{Pr}}$ in the ${ }^{140} \mathrm{Nd}$-DOTA eluate may be described as follows:

$$
A_{140 \mathrm{Pr}}=\zeta+\left(A_{140{ }_{\mathrm{Nd}}}-\zeta\right)\left(1-\exp \left(-\lambda{ }_{140_{\mathrm{Pr}}} t\right)\right)
$$

where $\zeta$ is the breakthrough of ${ }^{140} \mathrm{Pr}$ through the column, $A_{140}$ Nd the initial activity of ${ }^{140} \mathrm{Nd}$ in the system, $\lambda_{1400_{\mathrm{Pr}}}$ the decay constant of ${ }^{140} \mathrm{Pr}\left(3.4 \times 10^{-3} \mathrm{~s}^{-1}\right)$. While the lanthanide

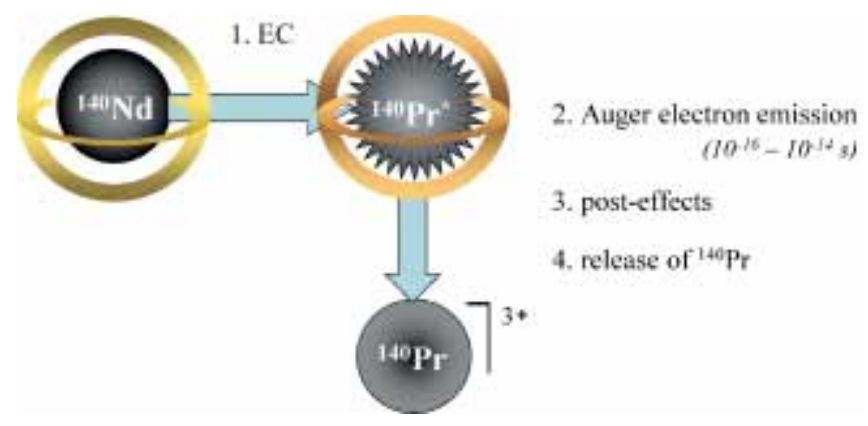

Fig. 6. A simplified scheme of ${ }^{140} \mathrm{Pr}$ release from the initial complex after electron capture decay of the parent ${ }^{140} \mathrm{Nd}$.

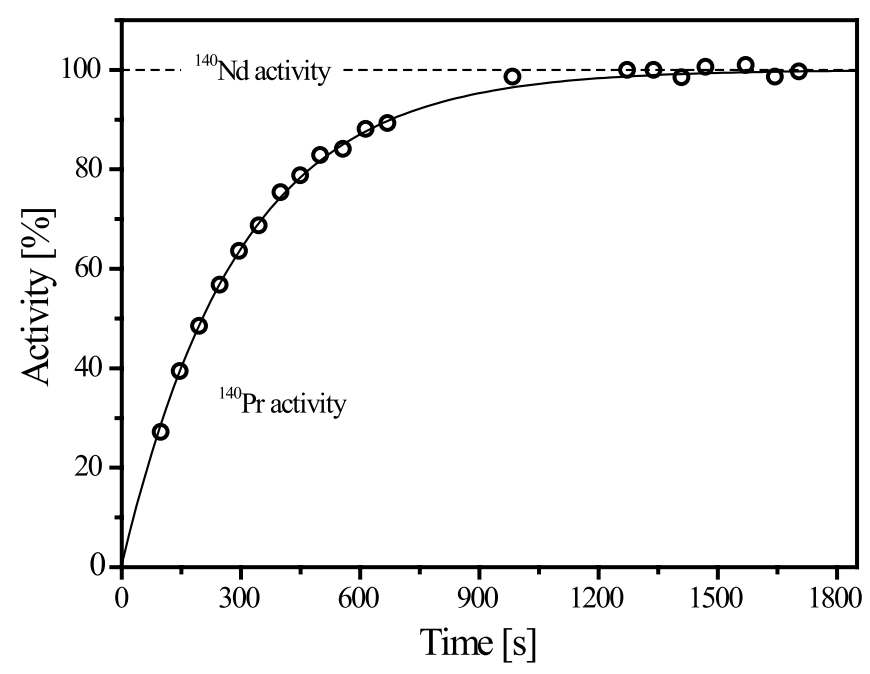

Fig. 7. Accumulation of ${ }^{140} \mathrm{Pr}$-activity in the ${ }^{140} \mathrm{Nd}$-DOTA eluate after separation of ${ }^{140} \operatorname{Pr}(\mathrm{III})$ on the micro-chromatography column in aqueous solution. The solid line represents the fitting of the experimental data with Eq. (1). 
exchange is inhibited by the kinetic inertness of the ${ }^{140} \mathrm{Nd}$ DOTA complex, $\zeta$ reflects the fraction of the generated radionuclide ${ }^{140} \mathrm{Pr}$ retained in the form of a DOTA complex (first retention). An example of data treatment is presented in Fig. 7. Fitting the experimental data (solid line in Fig. 7) with Eq. (1) leads to $\zeta=0.2(2) \%,\left(R^{2}=0.9981\right)$. The estimated inaccuracy in the experimental performance is $3 \%-5 \%$ and is due to non-instantaneous elution of the micro-chromatography column.

The main result of the study is that in aqueous medium not less than $95 \%$ of ${ }^{140} \mathrm{Pr}$ formed after the decay of ${ }^{140} \mathrm{Nd}$ is stabilized in a cationic form, i.e. not as ${ }^{140} \mathrm{Pr}$-DOTA species, and escapes from the DOTA complex.

\section{3 ${ }^{140} \mathrm{Nd} /{ }^{140} \mathrm{Pr}$ radionuclide generator}

Isolating ${ }^{140} \mathrm{Pr}$ from ${ }^{140} \mathrm{Nd}$-DOTA by means of cation exchange chromatography shows the principle of the hot atom chemistry-based separation strategy. It is, however, not an applicable radionuclide generator design, as the radionuclide generator mother nuclide is mobilised rather than immobilised. Consequently, further research was directed to an approach of chemically stable binding of ${ }^{140} \mathrm{Nd}$-DOTA on a stationary solid phase with subsequent elution of the ${ }^{140} \mathrm{Pr}$ released in an aqueous phase.

From our experience, DOTA-conjugated peptides (for instance DOTATOC) can be adsorbed on a solid reversed phase from aqueous solutions with a high distribution coefficient, while free lanthanide cations or simple lanthanide complexes can be eluted. A simplified illustration of the generator concept is shown in Fig. 8 (left side). The peptide is bound to the $\mathrm{C} 18$ cartridge. Due to the high thermodynamic stability and kinetic inertness of Ln-DOTA type complexes, the release of the longer-lived parent radionuclide ${ }^{140} \mathrm{Nd}$ is inhibited. Post-effects, on the other hand, lead to a release of the shorter-lived daughter radionuclide ${ }^{140} \mathrm{Pr}$. The generator column (Fig. 8 right side) could be operated with standard single-used syringes. Elution with $1 \mathrm{ml}$ of the eluate could be performed within about 10 seconds only.

\subsubsection{Elution yield}

After elution of the generator column, i.e. the $\mathrm{C} 18$ cartridge (Fig. 8, right side), the decay of ${ }^{140} \mathrm{Pr}$ obtained in the eluates

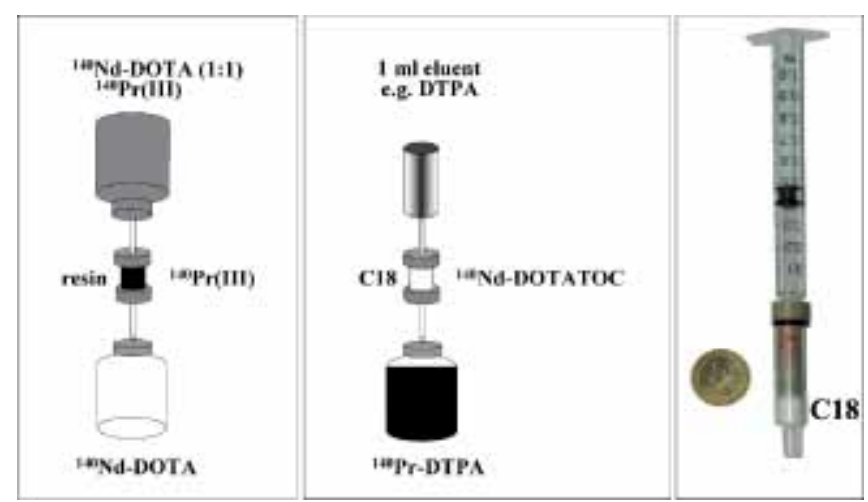

Fig. 8. A simplified illustration of the ${ }^{140} \mathrm{Nd} /{ }^{140} \mathrm{Pr}$ radionuclide generator concept (left side); the generator design (right side). was studied. The decrease of ${ }^{140} \mathrm{Pr}$ activity in the eluate may be described as follows:

$$
A_{140 \mathrm{Pr}}=\left(\xi A_{\mathrm{act}}{ }^{140} \mathrm{Nd}\right) \exp \left(-\lambda_{140 \mathrm{Pr}} t\right)
$$

where $A_{\text {act }{ }^{140} \mathrm{Nd}}$ is the actual (at elution time) activity of ${ }^{140} \mathrm{Nd}$, adsorbed on the column and $\xi$ is the fraction of the eluted ${ }^{140} \mathrm{Pr}$. The $\xi$-value represents the elution yield of the radionuclide generator. An example of data treatment after elution with $1 \mathrm{ml}$ of $10^{-3} \mathrm{M}$ DTPA is presented in Fig. 9 . Fitting of the experimental data (solid line in Fig. 9) with Eq. (2) leads to $\xi=0.97(7)$ (which is 97.5(7) \% elution yield), $\left(R^{2}=0.9997\right)$. An inaccuracy in the experimental performance is expected to be not more than 3\%-5\%.

The elution yield of ${ }^{140} \mathrm{Pr}$ in DTPA, citrate and NTA solutions is presented in Fig. 10 as a function of the ligand concentration. Not less than $93 \%$ of ${ }^{140} \mathrm{Pr}$ activity could be obtained in $1 \mathrm{ml}$ of $10^{-3} \mathrm{M}$ DTPA eluate. The elution yield decreased with decreasing ligand concentration and

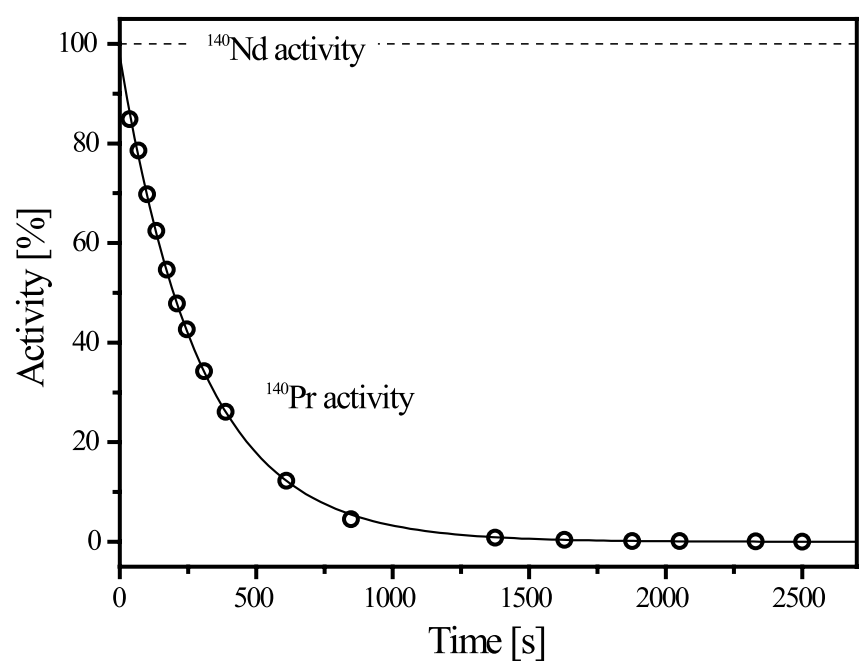

Fig. 9. The decay of ${ }^{140} \mathrm{Pr}$ after an elution of the generator $(2 \mathrm{MBq}$ of ${ }^{140} \mathrm{Nd}$ initial activity) with $1 \mathrm{ml}$ of $10^{-3} \mathrm{M}$ DTPA solution. The solid line represents the fitting of the experimental data with Eq. (2).

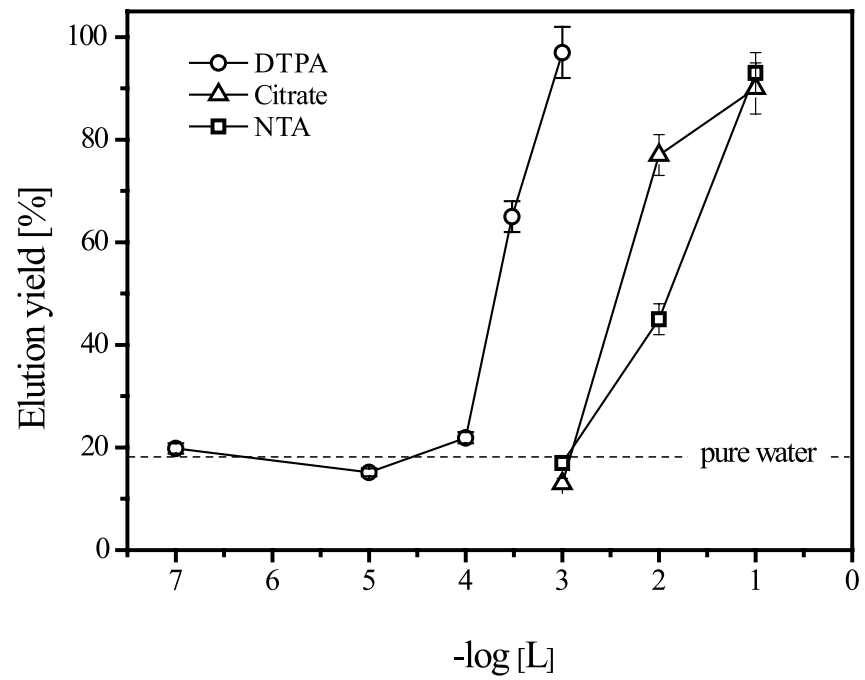

Fig. 10. Elution yield of ${ }^{140} \mathrm{Pr}$ in $1 \mathrm{ml}$ of aqueous solutions of DTPA (circles); citrate (triangles); NTA (squares) as a function of ligand concentration. 
was around $20 \%$ at a concentration $\leq 10^{-4} \mathrm{M}$ DTPA. The elution capacity of citrate and NTA was evidently poorer. About $90 \%$ of ${ }^{140} \mathrm{Pr}$ could be eluted only at $0.1 \mathrm{M}$ concentration of citrate and NTA solutions. This obviously is due to lower complex stability of the trivalent $\operatorname{Pr}(\mathrm{III})$ lanthanide with citrate and NTA ligands. About $20 \%$ of ${ }^{140} \operatorname{Pr}$ (III) could be eluted with $1 \mathrm{ml}$ of pure water.

\subsubsection{Breakthrough of ${ }^{140} \mathrm{Nd}$ and radionuclide generator stability}

The stability of the system was evaluated for the generator with $2 \mathrm{MBq}$ initial activity. Aqueous solutions of DTPA of $10^{-3} \mathrm{M}$ concentration were used as eluents. The breakthrough of ${ }^{140} \mathrm{Nd}$ in the eluate was measured for at least 10 half-lives of ${ }^{140} \mathrm{Pr}$ after the corresponding radionuclide generator elution. A constant level of ${ }^{140} \mathrm{Pr}$ was observed, as generated by the percentage of co-eluted ${ }^{140} \mathrm{Nd}$.

In order to evaluate the breakthrough of ${ }^{140} \mathrm{Nd}$ in the form of ${ }^{140} \mathrm{Nd}$-DOTATOC complex, the generator was eluted at first with $6 \mathrm{ml}$ of $10^{-3} \mathrm{M}$ DTPA solution. It allowed removal of all possible uncomplexed form of ${ }^{140} \mathrm{Nd}(\mathrm{III})$. Immediately there after the column was washed with $1 \mathrm{ml}$ of the eluent. In this eluate ${ }^{140} \mathrm{Nd}$ was observed in an amount of $1.5(5) \times 10^{-3} \%$ of the actual generator activity. This fraction was referred to as "stable breakthrough" of ${ }^{140} \mathrm{Nd}$ DOTATOC, following an elution with $1 \mathrm{ml}$ of $10^{-3} \mathrm{M}$ DTPA solution.

The overall breakthrough of the parent radionuclide, however, was found to increase with the increasing time between successive elutions. It is mainly because of radiolytic decomposition of the initial chemical form of the parent radionuclide $\left({ }^{140} \mathrm{Nd}\right.$-DOTATOC) and reflects the integral radiation dose adsorbed in the system. The fixed form of the parent radionuclide, if decomposed, provides the free form of ${ }^{140} \mathrm{Nd}$ which will be obtained in the eluate along with the daughter ${ }^{140} \mathrm{Pr}$. Therefore, in the presented system the radiolytic stability can play a key role and has to be quantitatively estimated.

To link the breakthrough fraction, caused by the radiolytic instability of the system, with the period of time between elutions (and therefore with integral adsorbed dose) a coefficient $K_{\mathrm{r}}\left[\mathrm{h}^{-1}\right]$ (Fig. 11) was calculated according to:

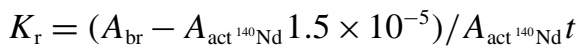

where $A_{\mathrm{br}}$ is the breakthrough of ${ }^{140} \mathrm{Nd}$ in the eluate, $t[\mathrm{~h}]$ the period of time passed from the last elution. The value $\left(A_{\text {act }}{ }^{140} \mathrm{Nd} 1.5 \times 10^{-5}\right)$ considers the constant fraction of ${ }^{140} \mathrm{Nd}$ washed out in the form of ${ }^{140} \mathrm{Nd}$-DOTATOC complex. $K_{\mathrm{r}} \mathrm{de}$ creased proportionally to the decay of ${ }^{140} \mathrm{Nd}$ (solid line in Fig. 11). It reflects a lower integral radiation dose received from decreasing ${ }^{140} \mathrm{Nd}$ activity in the system.

By normalization of $K_{\mathrm{r}}$ to the actual activity of ${ }^{140} \mathrm{Nd}$ $A_{\text {act }{ }^{10} \mathrm{Nd}}[\mathrm{MBq}]$, the coefficient $K_{\mathrm{r}}^{*}\left[\mathrm{MBq}^{-1} \mathrm{~h}^{-1}\right]$ (Fig. 11) could be obtained. $K_{\mathrm{r}}^{*}$ allows a quantitative evaluation of the radiolytic stability of the system. Thus for different actual activity of ${ }^{140} \mathrm{Nd}$ and time between successive elutions, the breakthrough fraction caused by radiolytic decomposition can be estimated.

The mean $K_{\mathrm{r}}^{*}$ value (solid line in Fig. 12) was derived to be $4.9(9) \times 10^{-6}\left[\mathrm{MBq}^{-1} \mathrm{~h}^{-1}\right]$. Thus for a system with

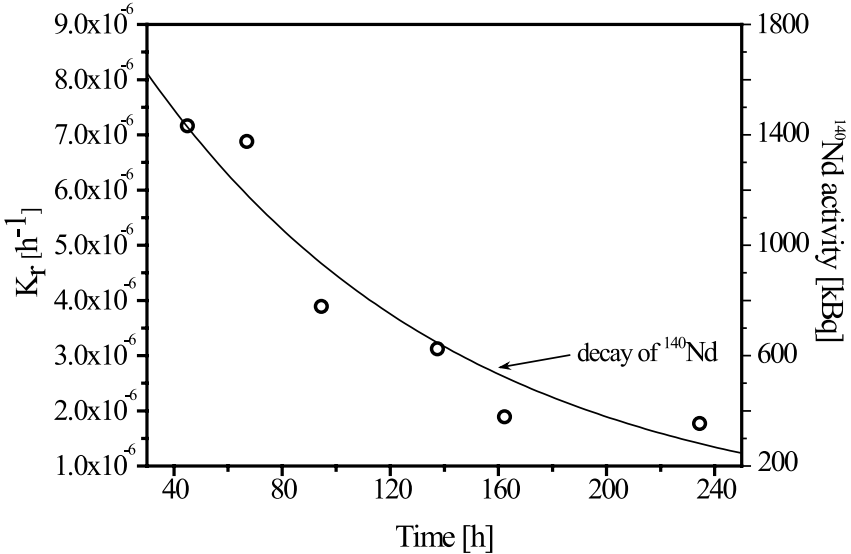

Fig. 11. Coefficient $K_{\mathrm{r}}\left[\mathrm{h}^{-1}\right]$ (Eq. (3)) as a function of time (observed from the moment of the generator loading); the solid line reflects the decay of ${ }^{140} \mathrm{Nd}$.

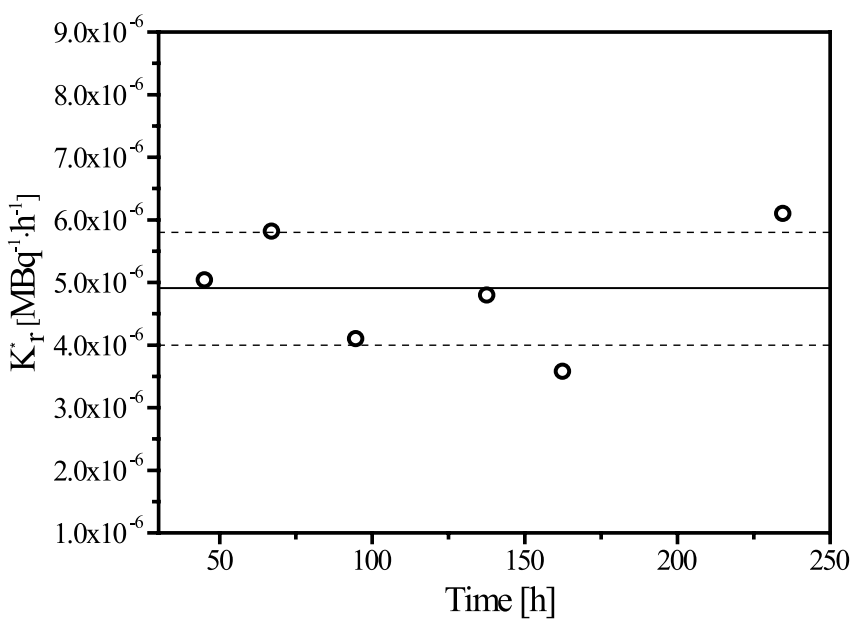

Fig. 12. $K_{\mathrm{r}}\left[\mathrm{h}^{-1}\right]$ normalized to the actual activity of ${ }^{140} \mathrm{Nd}[\mathrm{MBq}]$; the solid line represents the mean $K_{\mathrm{r}}^{*}$ value of $4.9 \times 10^{-6}\left[\mathrm{MBq}^{-1} \mathrm{~h}^{-1}\right]$ and the dotted lines give one standard deviation.

an actual ${ }^{140} \mathrm{Nd}$ activity of about $100 \mathrm{MBq}$ and $0.5 \mathrm{~h}$ time lapse after the last elution (time enough for accumulation of ${ }^{140} \mathrm{Pr}$ activity), a breakthrough of about $25 \mathrm{kBq}$ of ${ }^{140} \mathrm{Nd}$ $(\sim 0.025 \%)$ could be expected.

The presented generator design shows high elution yield and high chemical and radiochemical stability. The activity of the generated daughter nuclide allows for in vivo PET investigations and can be provided by a safe and simple operation in a clinical environment. The developed radionuclide generator represents the first adequate system, which allows rapid and efficient continuous separation of two neighbouring lanthanides. The system is applicable to ${ }^{140} \mathrm{Nd} /{ }^{140} \mathrm{Pr}$ but also for pair such as ${ }^{134} \mathrm{Ce} /{ }^{134} \mathrm{La}$. It combines hot-atom chemistry, in particular post-effects of nuclear transformation, with chemical consequences relevant for lanthanide speciation. Together with the adequate thermodynamic and kinetic stabilities of the macrocyclic chelator DOTA, the concept allows an efficient radiochemical separation.

In the present study, DOTA was selected as the chelate for ${ }^{140} \mathrm{Nd}$. However, there are other chelates with adequate thermodynamic and kinetic parameters relevant for trivalent lanthanides. In order to design a radiochemical radionuclide generator design, the ${ }^{140} \mathrm{Nd}$-DOTA complex was adsorbed 
on a solid resin via an octreotide modification of the DOTA structure, because the octapeptide octreotide strongly binds to reversed phase $\mathrm{C} 18$ matrices. Octreoide was selected mainly because of the commercial availability of DOTADPhe ${ }^{1}$-octreotide derivatives such as DOTATOC. Other peptides may be used as well for fixing the ${ }^{140} \mathrm{Nd}$-DOTA moiety to $\mathrm{C} 18$ cartridges. Alternatively, the strong adsorption of this ${ }^{140} \mathrm{Nd}$-DOTA moiety can be arranged by functionalising the DOTA structure in a variety of different ways, providing strong binding on different solid phases. Finally, complex structures may be modified in order to regulate parameters like lipophilicity, for example, allowing liquid/liquid separation systems between organic and aqueous solutions.

Potential directions for ${ }^{140} \mathrm{Nd} /{ }^{140} \mathrm{Pr}$ radionuclide generator applications could be PET studies with simple ${ }^{140} \mathrm{Pr}$ complexes, such as ${ }^{140} \mathrm{Pr}$-DTPA. This complex can be useful as a PET tracer, comparable to several DTPA based Gd complexes as used for MRT or ${ }^{99 \mathrm{~m}} \mathrm{Tc}-\mathrm{DTPA}$ in SPECT imaging. Another potentially important application could be as ${ }^{140} \mathrm{Pr}$-phosphonate complexes for visualisation of skeletal metastases. The radiolanthanide labelled ${ }^{153} \mathrm{Sm}$-EDTMP (1,2-diaminoethanetetrakis methylenephosphonic acid) for example, has useful pharmacological properties and is used clinically as a radiotherapeutic agent for bone cancer treatment. The phosphonate complexes such as EDTMP are structure analogues to the aminopolycarboxylates (DTPA, NTA), providing also high thermodynamic stability of their complexes. Use of EDTMP as an eluent for the presented ${ }^{140} \mathrm{Nd} /{ }^{140} \mathrm{Pr}$ radionuclide generator system could provide further potentially useful ${ }^{140} \mathrm{Pr}$-complexes for repetitive intravenous injections.

\section{Conclusions}

The radionuclide ${ }^{140} \mathrm{Nd}$ was produced in quantities between 35 and $200 \mathrm{MBq}$ via the nuclear processes ${ }^{\text {nat }} \mathrm{Ce}\left({ }^{3} \mathrm{He}, x n\right)$ and ${ }^{141} \operatorname{Pr}(p, 2 n)$ at a medium-sized cyclotron. Even at a nominal proton energy of $18.6 \mathrm{MeV}$ the yield via the latter process was about four times higher than via the former route at $33.5 \mathrm{MeV}$. Chemical isolation of ${ }^{140} \mathrm{Nd}$ (III) from macro amounts of $\mathrm{Ce}(\mathrm{III})$ and $\operatorname{Pr}(\mathrm{III})$ could be performed by cation-exchange chromatography (two purification steps only) with overall decontamination factor from the respective target material of $\sim 10^{8}$ and $7 \times 10^{5}$. ${ }^{140} \mathrm{Nd}$ can be successfully used for preparation of metalloradiopharmaceuticals with high specific activities.

An efficient ${ }^{140} \mathrm{Nd} /{ }^{140} \mathrm{Pr}$ radionuclide generator system has been developed. It combines an aspect of hot atom chemistry, in particular post-effects of nuclear transformation, with chemical consequences relevant to lanthanide speciation. Together with the adequate thermodynamic and kinetic stabilities of the macrocyclic chelator DOTA, the concept allows for an efficient radiochemical separation. The presented generator design shows high elution yield and high chemical and radiochemical stability. The activity of the generated daughter nuclide is enough for in vivo PET investigations and it can be provided by safe and simple operation in a clinical environment. The developed radionuclide generator represents the first satisfactory system, for rapid, efficient and continuous separation of two neighbouring lanthanides. The system is applicable to ${ }^{140} \mathrm{Nd} /{ }^{140} \mathrm{Pr}$ but also to a pair such as ${ }^{144} \mathrm{Ce} /{ }^{134} \mathrm{La}$.

By virtue of very high elution yield and high chemical and radiochemical stability, the system is able to provide the short-lived positron-emitting radiolanthanide ${ }^{140} \mathrm{Pr}$ for PET investigations. The design resulted in small eluate volumes and could allow safe repetitive injections of, e.g., ${ }^{140} \mathrm{Pr}$ DTPA.

The potential use of ${ }^{140} \mathrm{Nd} /{ }^{140} \mathrm{Pr}$ as an in vivo radionuclide generator, however, needs to be studied in more detail. The generation of ${ }^{140} \mathrm{Pr}$ may result in a different chemical form of ${ }^{140} \mathrm{Pr}$ as compared to the initially applied ${ }^{140} \mathrm{Nd}$ labelled compound. This might disturb imaging qualities. Thus, in contrast to the desired parameters of DOTA ligands, in vivo generator systems should utilize chemical forms of ${ }^{140} \mathrm{Nd}$, which prevent release of ${ }^{140} \mathrm{Pr}$.

Acknowledgment. The authors would like to acknowledge support via the COST D18 action and the Deutsche Forschungsgemeinschaft (grant DFG Ro 985/10-1,2). Acknowledgement is made to the operators of the compact cyclotron CV 28 at Jülich for performing the irradiations and Mr. S. Spellerberg for experimental assistance.

\section{References}

1. Rösch, F., Knapp, F. F.: Radionuclide Generators. In: Handbook of Nuclear Chemistry. (Vértes, A., Nagy, S., Klencsár, Z., eds.) Kluwer, Amsterdam (2003), vol.4, p. 81.

2. Rösch, F., Brockmann, J., Lebedev, N. A., Qaim, S. M.: Production and radiochemical separation of the Auger electron emitter ${ }^{140} \mathrm{Nd}$. Acta Oncol. 39, 727 (2000).

3. Rösch, F., Forssell-Aronsson, E.: Radiolanthanides in Nuclear Medicine. In: Metals Ions in Biological Systems. (Sigel, A., Sigel, H., eds.) New York - Basel (2004), vol.42, p. 77.

4. Segrè, E., Halford, R. S., Seaborg, G. T.: Chemical separation of nuclear isomers. Phys. Rev. 55, 321 (1939).

5. Stenström, T., Jung, B.: Rapid chemical separation of isomeric states of lanthanides. Radiochim. Acta 4, 3 (1965).

6. Mirzadeh, S., Kumar, K., Gansow, O. A.: The chemical fate of ${ }^{212} \mathrm{Bi}$-DOTA formed by $\beta$-decay of ${ }^{212} \mathrm{~Pb}$ (DOTA). Radiochim. Acta 60, 1 (1993).

7. Beyer, G. J., Grosse-Ruyken, H., Khalkin, W. A.: Eine Methode zur Trennung genetisch verknüpfter isobarer und isomerer Nuklidpaare der Seltenen Erden. J. Inorg. Nucl. Chem. 31, 1865 (1969).

8. Qaim, S. M.: Measurement of $(n, p)$ reaction cross sections at 14.7 MeV using high-pressure liquid chromatography in the region of Rare Earths. Radiochem. Radioanal. Lett. 25, 335 (1976).

9. Caravan, P., Ellison, J. J., McMurry, T. J. Lauffer, R. B.: Gadolinium chelators as MRI contrast agents: structure, dynamics, and applications. Chem. Rev. 99, 2293 (1999).

10. Hilgers, K., Shubin, Y. N., Coenen, H. H., Qaim, S. M.: Experimental measurements and nuclear model calculation on the excitation functions of ${ }^{\text {nat }} \mathrm{Ce}\left({ }^{3} \mathrm{He}, x n\right)$ and ${ }^{141} \mathrm{Pr}(p, x n)$ reactions with special reference to production of the therapeutic radionuclide ${ }^{140} \mathrm{Nd}$. Radiochim. Acta 93, 553 (2005).

11. Browne, E., Firestone, R. B.: Table of Radioactive Isotopes. (Shirley, V. S., ed.) John Wiley \& Sons, New York (1986). 